\title{
ATI718PLUS® - NEW NICKEL BASED DISC ALLOY AND ITS CAPABILITY
}

\author{
D. Huenert ${ }^{1}$, M. Proebstle ${ }^{3}$, A. Casanova ${ }^{5}$, R. Schluetter ${ }^{1,5}$, R. Krakow ${ }^{1,5}$, M. Buescher ${ }^{2}$, P. Randelzhofer ${ }^{4}$, A. Evans $^{1}$, K. Loehnert $^{1}$, T. \\ Witulski ${ }^{2}$, S. Neumeier ${ }^{3}$, C. Rae $^{5}$ \\ 1 Rolls Royce Deutschland, Blankenfelde-Mahlow, Germany \\ 2 Otto Fuchs KG, Meinerzhagen, Germany \\ 3 Friedrich-Alexander University Erlangen-Nürnberg, Germany, Institute of General Materials Properties \\ 4 Friedrich-Alexander University Erlangen-Nürnberg Germany, Institute of Metals Science and Technology \\ 5 Department of Materials Science and Metallurgy, University of Cambridge, 27 Charles Babbage Road, Cambridge CB3 0FS, UK
}

Keywords: ATI718Plus ${ }^{\circledR}$ alloy; FCG; tensile; creep; oxidation; long term stability

\begin{abstract}
Two extreme microstructural variants of alloy ATI718PLUS ${ }^{\circledR}$ were investigated regarding their tensile strength, creep resistance, long-term stability, oxidation and crack growth properties. The variants were produced by supersolvus and subsolvus forging procedures. A subsolvus forging produces fine-grained microstructure with aligned blocky secondary $\eta$-phase. The supersolvus forging generated a coarser grain size with improved creep performance and non-aligned lamellar $\eta$-phase. The oxidation behavior has been characterized showing superior performance of ATI718PLUS ${ }^{\circledR}$ relative to alloy 718 and 720LI. The results have been used to design optimized microstructures balancing the properties required for critical rotating parts. The analysis of several test conditions show, that key properties can be altered over a wide range.
\end{abstract}

\section{Introduction}

Critical rotating components such as discs require an alloy with an excellent combination of strength, damage tolerance, creep and oxidation resistance, properties that are stable over the lifetime of the component.

Within Rolls-Royce Deutschland (RRD), alloy 718 and 720Li are the most commonly used nickel-based superalloys for critical rotating parts such as compressor and turbine discs. The typical upper operating temperature of alloy 718 is $630{ }^{\circ} \mathrm{C}$ and that of alloy $720 \mathrm{LI}$ is $700{ }^{\circ} \mathrm{C}$. ATI Specialty Materials (ATI) has developed a new nickel-based superalloy called ATI718Plus ${ }^{\circledR}$ (A718Plus) that combines the desirable processability and weldability of 718 with the higher temperature capability and thermal stability of 720LI [1].

Consequently, the microstructure of A718Plus has been optimized by forging and heat treatment to achieve the required combination of strength, damage tolerance and creep resistance essential for critical rotating components. Within a close collaborative work between RRD, Otto Fuchs KG, and the Universities of ErlangenNürnberg and Cambridge, different microstructures were investigated to find an optimal combination of properties [1-8]. This paper shows the extreme variants that can be produced by different manufacturing routes and highlights the limits of the achieved properties. The reported results have been used to design an optimized microstructure. Specifically, A718Plus closes a gap in the application of disc alloys in the temperature range where the operation of alloy 718 is limited and the potential of alloy $720 \mathrm{LI}$ is not required.

\section{Processing of A718Plus}

The manufacturing of a superalloy turbine disc typically involves hot-forming a billet in several steps to obtain the desired disc geometry and to refine the microstructure. The subsequent heat treatment adjusts the second phase precipitate populations and associated strengthening.

All experiments were carried out on A718Plus nickel base alloy produced by ATI Specialty Materials. The billet material was a triple vacuum melted ingot with the chemical composition shown in Table 1.

Table I. chemical composition of A718Plus

\begin{tabular}{|l|l|l|l|l|l|l|l|l|l|}
\hline wt $\%$ & $\mathrm{Cr}$ & $\mathrm{Fe}$ & $\mathrm{Co}$ & $\mathrm{Mo}$ & $\mathrm{W}$ & $\mathrm{Nb}$ & $\mathrm{Al}$ & $\mathrm{Ti}$ & $\mathrm{C}$ \\
\hline $\min$ & 17.0 & 8.0 & 8.0 & 2.5 & 0.8 & 5.2 & 1.2 & 0.5 & 0.01 \\
\hline $\max$ & 21.0 & 10.0 & 10.0 & 3.1 & 1.4 & 5.8 & 1.7 & 1.0 & 0.05 \\
\hline
\end{tabular}

A subsolvus and a supersolvus forging route was carried out by Otto Fuchs KG, Meinerzhagen, in order to study the extremes of the microstructure and give a basis for an optimized microstructure balancing the properties required for critical components.

After forging, the disc was subjected to a standard heat treatment recommended by ATI Allvac [9]:

Pre-solution: $843{ }^{\circ} \mathrm{C}-871{ }^{\circ} \mathrm{C} / 16 \mathrm{~h} / \mathrm{AC}$

Solution: $954^{\circ} \mathrm{C}-982{ }^{\circ} \mathrm{C} / 1 \mathrm{~h} / \mathrm{AC}$

Double Aging: $788^{\circ} \mathrm{C} / 2 \mathrm{~h}-8 \mathrm{~h} / \mathrm{FC}+704{ }^{\circ} \mathrm{C} / 8 \mathrm{~h} / \mathrm{AC}$

\section{Experimental methods}

Preparation and microstructural characterization techniques The A718Plus variants were microstructurally characterized using scanning electron microscope (SEM) Zeiss Crossbeam 1540 EsB, the FIB/SEM FEI Helios NanoLab, as well as the transmission electron microscope (TEM) Phillips CM200. For SEM investigations, the samples were ground to $5 \mu \mathrm{m}$ grit size, mechanically polished to a final step of $1 \mu \mathrm{m}$ diamond suspension and afterwards oxide polished by OPU (Struers GmbH, Germany).

The micrographs were acquired using the backscattered electrons (BSE) contrast at a working distance of $7.5 \mathrm{~mm}$. To determine the grain size via linear intercept method and to quantify the $\eta$ phase area fraction, the micrographs were subsequently converted to binary images using the open source image processing package Fiji and the available tool Trainable Weka Segmentation. To describe the aspect ratio and the alignment of the $\eta$ precipitates, 
the particles were fitted by an ellipse. The average values for the $\eta$ area fraction were calculated by evaluation of four images covering an area of $56 \mu \mathrm{m} \times 39 \mu \mathrm{m}$. To determine the grain size of the cross-stitched microstructure micrographs with the size 227 $\mu \mathrm{m} \times 158 \mu \mathrm{m}$ were analyzed. The TEM samples were thinned by mechanical grinding to a thickness of around $100 \mu \mathrm{m}$ and afterwards thinned by twin jet polishing using an agent of ethanol and perchloric acid (Electrolyte A2, Struers GmbH, Germany) at a temperature of $-30{ }^{\circ} \mathrm{C}$. The TEM investigations were performed in the dark field mode at an accelerating voltage of $200 \mathrm{kV}$ using the [001] zone axis and [001] diffraction spots of the $\gamma^{\prime}$-phase. The images were recorded via the installed $2 \mathrm{k} \times 2 \mathrm{k}$ CMOS camera F216 (TVIPS).

\section{$\underline{\text { Simulation }}$}

The simulation software Simufact GP 11.0 is the standard tool to predict temperature and strain distribution as well as the associated grain size and degree of recrystallization within a forging. Within this publication, the prediction of the arrangement of the secondary precipitations is shown.

\section{$\underline{\text { Tensile Tests }}$}

Tensile tests were performed according to BS EN2002-2 on a test piece with $5 \mathrm{~mm}$ diameter at $600{ }^{\circ} \mathrm{C}$. The test piece was strained up to proof stress $\mathrm{R}_{\mathrm{P} 0.2}$ at a velocity of $0.003 / \mathrm{min}$ and beyond that at a rate of $0.1 / \mathrm{min}$.

\section{$\underline{\text { Oxidation Tests }}$}

A vertical tube furnace with an integrated thermos balance was used to oxidize samples with plate geometry of $20 \times 20 \times 2 \mathrm{~mm}$ providing an optimal ratio of surface to volume and weight. The tests were performed in a temperature range from $650{ }^{\circ} \mathrm{C}$ to 1000 ${ }^{\circ} \mathrm{C}$ under dry synthetic air (20 vol.- $\% \mathrm{O}_{2}, 80$ vol.- $\% \mathrm{~N}_{2}$; flowrate $200 \mathrm{ml} / \mathrm{min}$ )

\section{Creep tests:}

The tensile creep experiments were performed at a constant stress of $650 \mathrm{MPa}$ and the temperature of $650{ }^{\circ} \mathrm{C}$ using specimen with a circular cross section and a diameter of $5.6 \mathrm{~mm}$. The material used for the characterization of the thermal stability differs from the investigated variants within this study and details regarding the microstructure can be found elsewhere [7]. The material was longterm exposed at $680{ }^{\circ} \mathrm{C}$ and $700{ }^{\circ} \mathrm{C}$ for 500 hours to study the degrading mechanism and the influence on the creep resistance.

\section{Crack growth}

The fatigue crack growth (FCG) rates were determined under constant load on test pieces with corner crack geometry according to DIN EN 3873 with a cross section of $7 \times 7 \mathrm{~mm}^{2}$ (Figure 1). The test pieces were positioned on the same radius but orientated in different directions as indicated in Figure 1. The axes marked as $0^{\circ}$ corresponds to the axial direction, $90^{\circ}$-a to the radial direction and $90^{\circ}-\mathrm{b}$ to the tangential direction of a forging.

Trapezoid wave with $1 \mathrm{~s}$ and $120 \mathrm{~s}$ loading at maximum stress at $650{ }^{\circ} \mathrm{C}$ in air and under vacuum, $\mathrm{R}=0.1$ were used as test conditions. The rate of crack growth $(\mathrm{da} / \mathrm{dN})$ found from potential drop analysis is determined as a function of the cyclic range of the crack tip stress intensity factor $(\Delta \mathrm{K})$ which is related to the test piece geometry and applied stress field:

$$
\frac{d a}{d n}=C \cdot \Delta K^{n}
$$

The resulting and fitted data are presented in a graphical manner with $\mathrm{C}$ and $\mathrm{n}$ values defining the 'Paris' region, or where steady state growth is experienced. The constants $\mathrm{C}$ and $\mathrm{n}$ are considered to be dependent on material, microstructure, environment and test frequency [10]

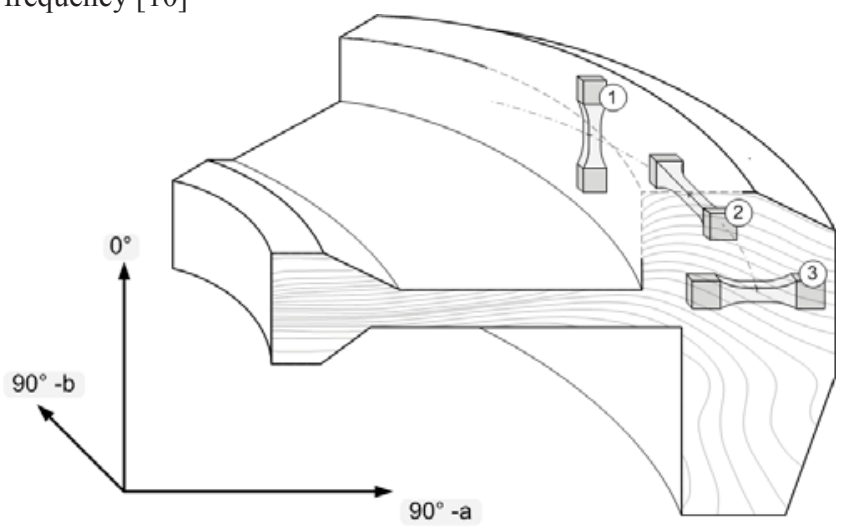

Figure 1. Forging simulation on a generic shape and positioning of corner crack test pieces

\section{Material and Microstructure}

A718Plus is designed to precipitate two principal secondary phases in the austenitic $\gamma$ matrix: i) fine and coherently precipitated $\gamma^{\prime}\left(\mathrm{Ni}_{3}[\mathrm{Al}, \mathrm{Nb}, \mathrm{Ti}]\right)$ and ii) coarse and acicular $\delta$ phase $\left(\mathrm{Ni}_{3} \mathrm{Nb}\right)$ at the grain boundaries [11]. The creep resistance, high-temperature stability and strength of the material are largely determined by $\gamma^{\prime}$, whilst the $\delta$-phase is intended to control grain size during forging and enhance intergranular crack propagation resistance. The nature of the grain boundary precipitation has been the subject of much discussion and investigation [11, 12]. Subsequently, it has been demonstrated by Pickering et al. [13] and Messé et al. [6] that the grain boundary precipitates consist of hexagonal $\eta$-plates $\left(\mathrm{Ni}_{6}[\mathrm{Al}, \mathrm{Ti}] \mathrm{Nb}\right)$ interleaved with thin layers of $\delta$. Further investigations by Casanova et al. have showed the presence of a dual population of $\eta$ precipitates, which are distinguished by blocky particles and cascades of thin lamellae [3]. The coherency of the interface, between the $\eta$ precipitate and the matrix has been identified as the origin of the different $\eta$ morphologies [2, 3]. Within this study, two microstructural extremes of A718Plus have been produced (Figure 2, Figure 3). The cross-stitched microstructural variant with mainly lamellar $\eta$ was produced via supersolvus forging and subsequent standard heat treatment (Figure 2). The colonies of thin lamellae have grown discontinuously during heat treatment into the grain with a coherent interface between the precipitate and the recrystallized strain-free $\gamma$ matrix and a Blackburn orientation relationship [13]. The microstructure reported by ATI [9] is similar to the crossstitched microstructure within this publication and therefore used as a reference.

The microstructure with the blocky $\eta$ phase was generated during subsolvus forging (Figure 3 ). The $\eta$ precipitates quickly lose coherency with the matrix through deformation and recrystallization. The increased mobility of the incoherent interface combined with high dislocation densities allows the formation of coarse plates. The two different morphologies of $\eta$ precipitates can be identified by evaluating their aspect ratio. The thin $\eta$ lamellae of the cross-stitched microstructure reveal significantly higher aspect ratio in comparison to the blocky type (see Figure 6). To illustrate the different degree of alignment, the accumulated frequency as a function of the orientation of the main 


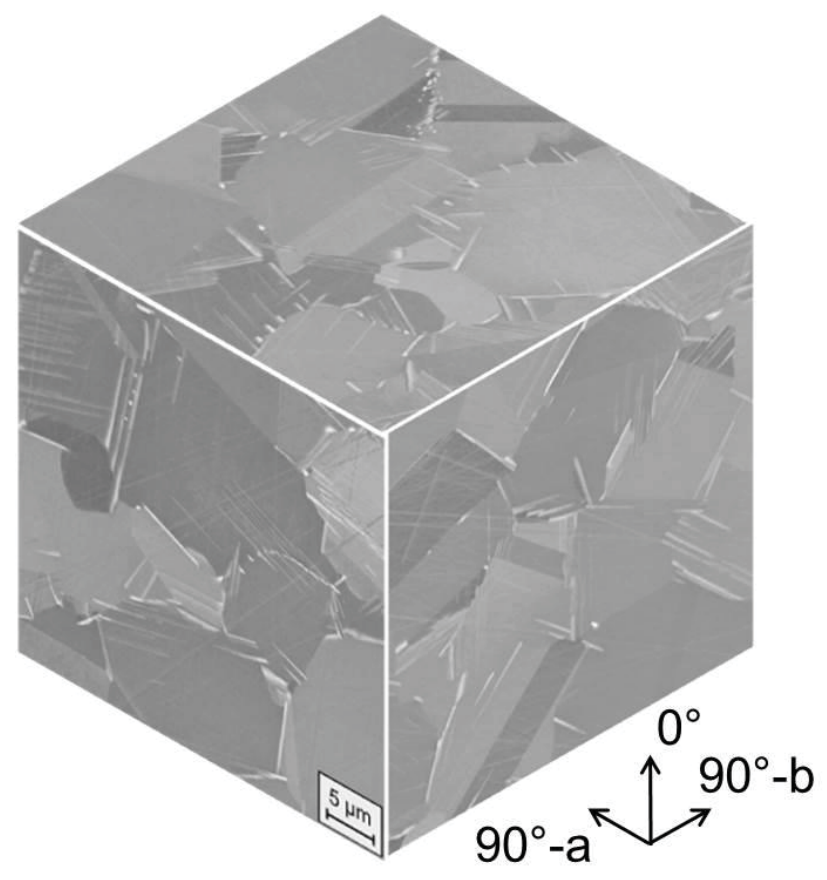

Figure 2. 3D SEM image of the cross-stitched microstructural variant of A718Plus received due to supersolvus forging and subsequent standard heat treatment. The thin lamellae of $\eta$ at the grain boundaries precipitate during the heat treatment and the growth direction is statistically distributed.

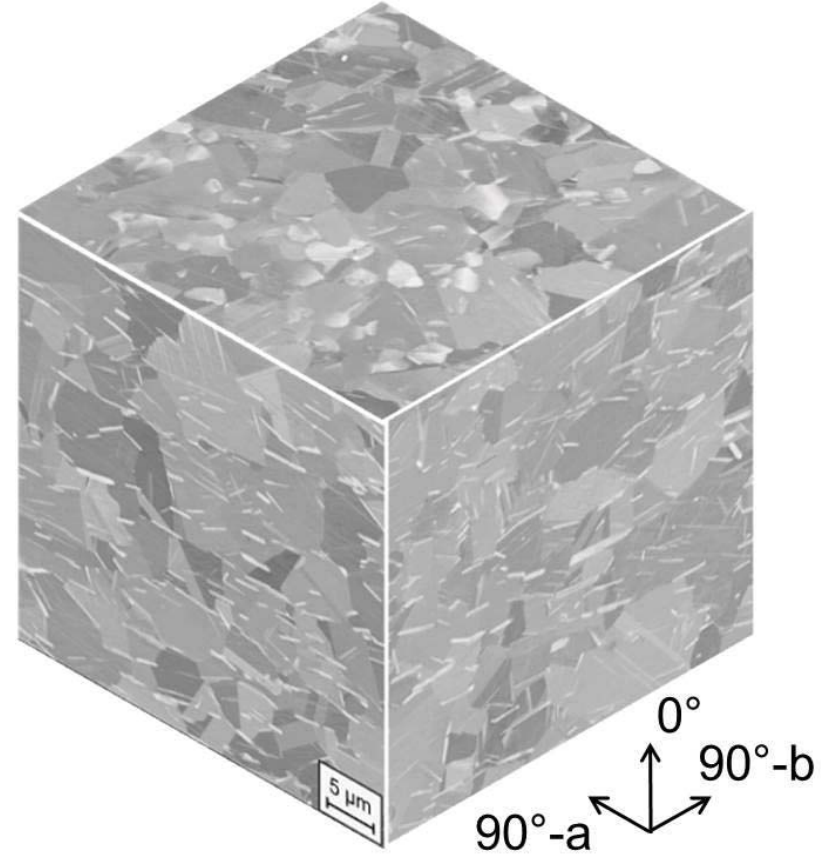

Figure 3. 3D SEM image of the aligned microstructural variant of A718Plus received due to subsolvus forging and subsequent standard heat treatment. The blocky $\eta$ plates along the grain boundaries show strong alignment to $0^{\circ}$.

axes of the precipitates is plotted in Figure 4 and 5. While the $\eta$ precipitates are randomly oriented in the cross-stitched microstructure (Figure 4), the blocky $\eta$ particles are strongly aligned parallel to $90^{\circ}$-a (Figure 5). The direction of the alignment within a component is dependent on the material flow during forging and can be predicted by applying simulation techniques, see section within experimental methods.

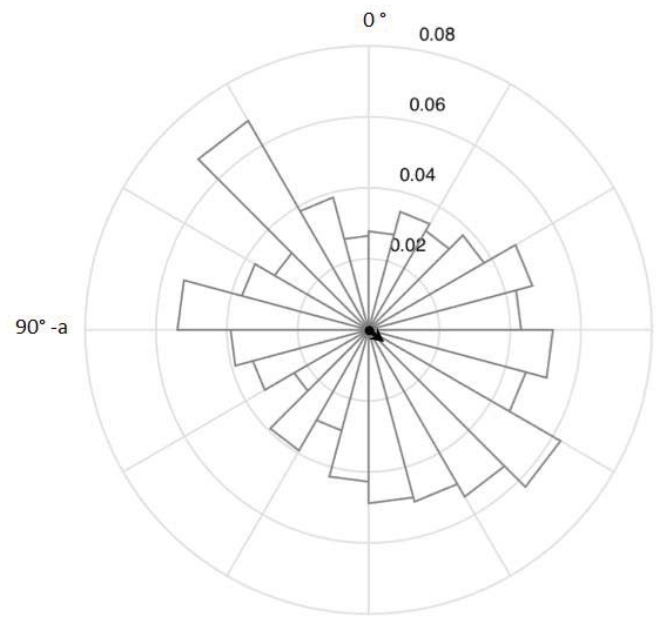

Figure 4. Polar diagram of the main axes of the $\eta$-plates, crossstitched microstructure.

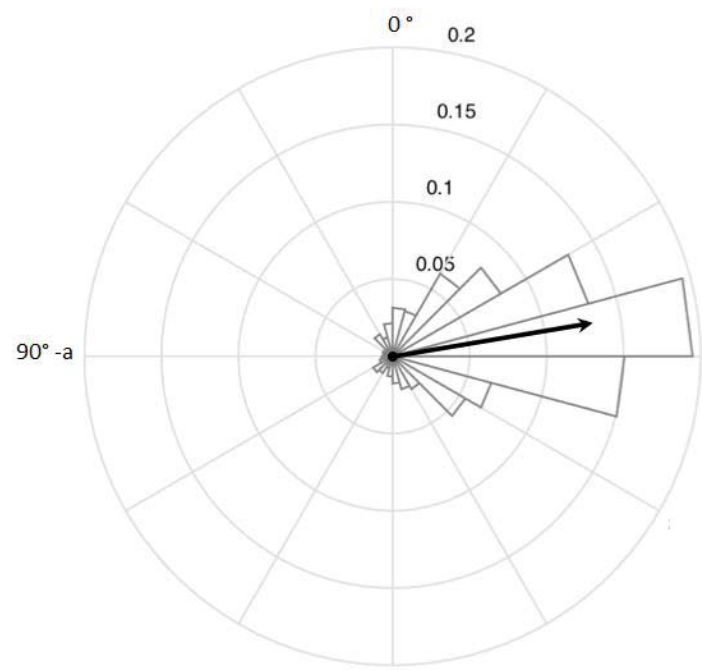

Figure 5. Polar diagram of the main axes of the $\eta$-plates, aligned microstructure.

Figure 1 shows the results of a simulation for a generic ultrasonic disc shape where the lines predict the direction of the main axes of the $\eta$ precipitates. By optimizing the material flow, the direction of the alignment can be adjusted. Moreover, the quantitative analysis of the two variants revealed a finer grain size and significantly higher $\eta$ area fraction for the aligned microstructure (Table II). This can be explained by the complete dissolution of $\eta$ phase during supersolvus forging combined with the occurrence of grain coarsening due to the lack of grain boundary pinning $\eta$ precipitates.

During precipitation, the secondary precipitates $\gamma^{\prime}$ and $\eta$ compete for the same elements: $\mathrm{Nb}, \mathrm{Al}$ and $\mathrm{Ti}$. Thus, the balance of these phases in the microstructure needs to be carefully adjusted. In 
Figure 10a the TEM dark field micrograph reveals the presence of spherical $\gamma^{\prime}$-particles having a uniform size of around $35 \mathrm{~nm}$ after

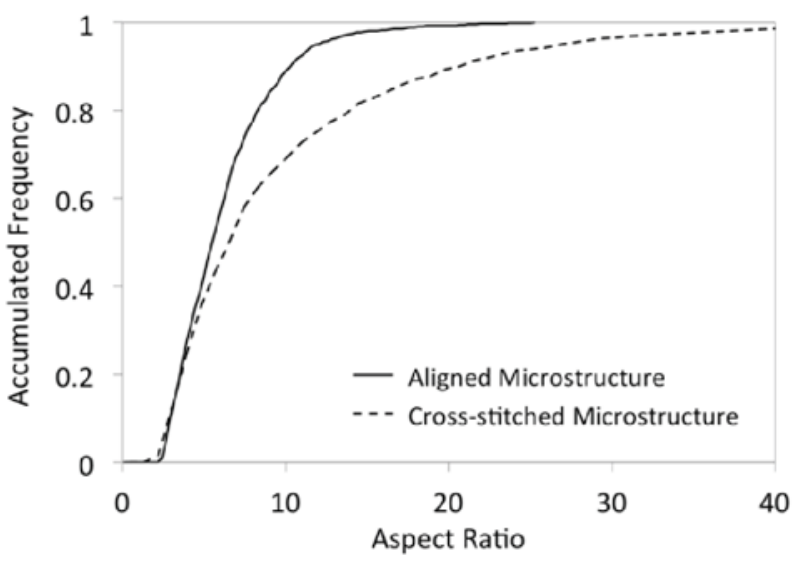

Figure 6. Accumulated frequency of the aspect ratio of the $\eta$ precipitates within the two different microstructural modifications.

the standard double aging heat treatment procedure. Since identical aging steps were applied to both variants, the $\gamma^{\prime}$-size is similar for both microstructures as shown in Figure 7.
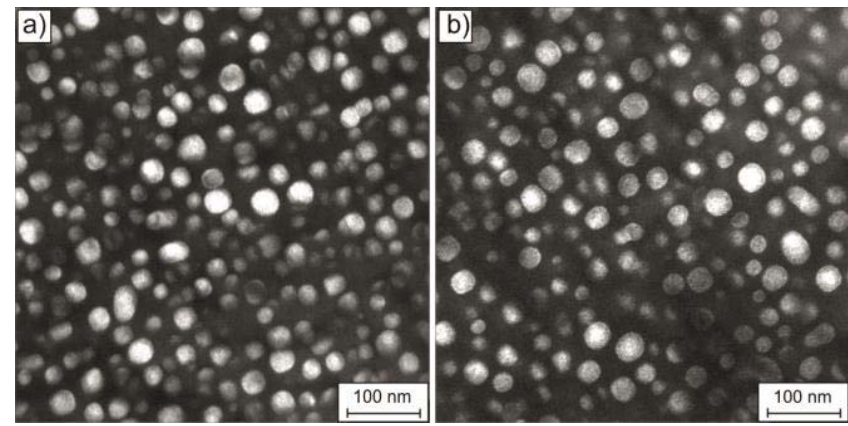

Figure 7. Dark field TEM micrographs of the $\gamma^{\prime}$ precipitates of the a) cross stitched and b) aligned microstructure.

Table II. Grain size and $\eta$-area fraction of the cross-stitched and aligned A718Plus variant investigated within this study.

\begin{tabular}{ccc}
\hline State & $\begin{array}{c}\text { Grain size } / \mu \mathrm{m} \\
(\text { Median } \pm \sigma)\end{array}$ & $\begin{array}{c}\eta \text {-Area Fraction } / \% \\
(\text { Average } \pm \sigma)\end{array}$ \\
\hline Cross-stitched & $11.6 \pm 7.3$ & $5.6 \pm 1.3$ \\
\hline Aligned & $3.3 \pm 2.0$ & $10.4 \pm 1.2$ \\
\hline
\end{tabular}

\section{Results and discussion}

\section{$\underline{\text { Tensile Properties }}$}

The different processing routes generating cross-stitched and aligned microstructure produce two classes of grain sizes in the resulting material: A microstructure with aligned $\eta$ shows a finegrained microstructure from ASTM 10 to 12. A cross-stitched microstructure has grain sizes from ASTM 6 to 9 attributed to grain growth during forging. The results of tensile testing at 600 ${ }^{\circ} \mathrm{C}$ of both cross-stitched and aligned microstructures are shown in
Figure 8, illustrating the proof strength and ultimate tensile strength over a range of grain sizes from ASTM 6 to ASTM 12. The data illustrated in Figure 8 can be described as follows: The proof stress ranges from around $880 \mathrm{MPa}$ for ASTM 6 to 945 $\mathrm{MPa}$ for ASTM 9 in the cross-stitched microstructure, and from around $1000 \mathrm{MPa}$ for ASTM 11 (and $1010 \mathrm{MPa}$ for ASTM 10.5) to $1070 \mathrm{MPa}$ for ASTM 11.5 and 12 in the aligned microstructure; both data sets follow a linear trend of increasing strength with decreasing grain sizes. The ultimate tensile strength for the crossstitched microstructure is on average $390 \mathrm{MPa}$ higher than its correspondent proof strength values. For the aligned microstructure the difference is $350 \mathrm{MPa}$ on average, showing a less pronounced linear increase with decreasing grain size in the aligned structure. The reduction in area is slightly higher for specimens with bigger grain sizes with $30-35 \%$ compared to $27-$ $32 \%$ for the samples with ASTM 10 and higher. No difference in elongation was observed between the two microstructures $(\sim 17 \%)$ and results are comparable to the ATI data. The same correlation, but slightly lower values are found in the ATI results.

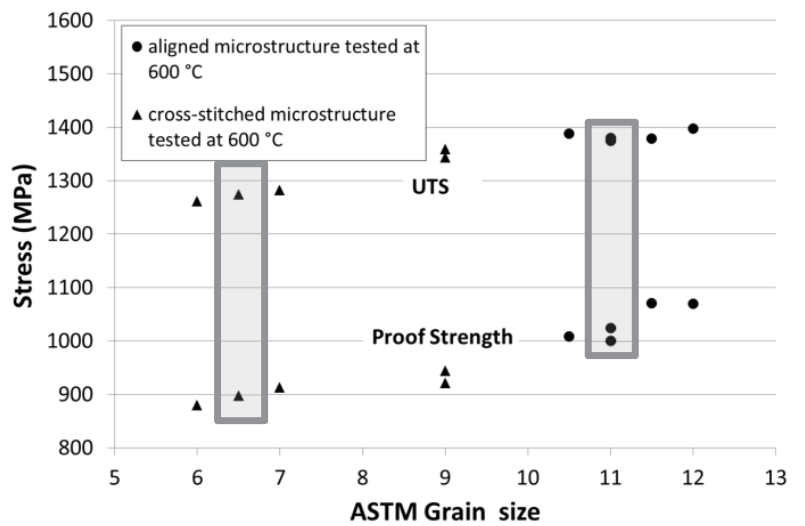

Figure 8. UTS and proof strength as a function of grain size for cross stitched microstructure and aligned microstructure.

The observed trend in the proof stresses of the two microstructures can be well correlated with the Hall-Petch relationship, which is described by $\Delta \sigma=K / \sqrt{d}$, where $\Delta \sigma$ is the grain boundary strengthening, $K$ the Hall-Petch constant and $d$ the mean grain size. The Hall-Petch constant for superalloys is taken to be $710 \mathrm{MPa}[\mu \mathrm{m})^{\wedge}(1 / 2)[14]$. The following example illustrates the correlation: The increase in strengthening from the minimum cross-stitched proof strength value to the maximum aligned value is $191 \mathrm{MPa}$ and the corresponding Hall-Petch calculates $169 \mathrm{MPa}$. The difference is below $25 \mathrm{MPa}$, which can be accounted for by the experimental scatter. This suggests that the two extreme microstructural variants are governed by the same strengthening mechanisms and differences are caused mainly by the spread in grain size.

\section{Creep resistance}

The creep behavior of A718Plus was evaluated at a stress of 650 $\mathrm{MPa}$ and a temperature of $650{ }^{\circ} \mathrm{C}$. Figure 9 shows that the crossstitched microstructure possesses superior creep strength with a significantly reduced minimum creep rate in comparison to the aligned microstructure. Studies of the creep resistance of alloy 718 have shown that power law creep is active and the effect of the different grain sizes is expected to be rather low [15]. Since both, the $\gamma^{\prime}$ and the $\eta$ phase consume the same elements, especially $\mathrm{Al}, \mathrm{Ti}$ and $\mathrm{Nb}$, the cross-stitched microstructure with 
the lower $\eta$ volume fraction is expected to have higher $\gamma^{\prime}$ volume fraction and hence better creep strength. Due to similar heat treatment the $\gamma^{\prime}$ size within both variants is similar; the differences regarding the creep resistance seem to result from different $\gamma^{\prime}$ volume fraction.
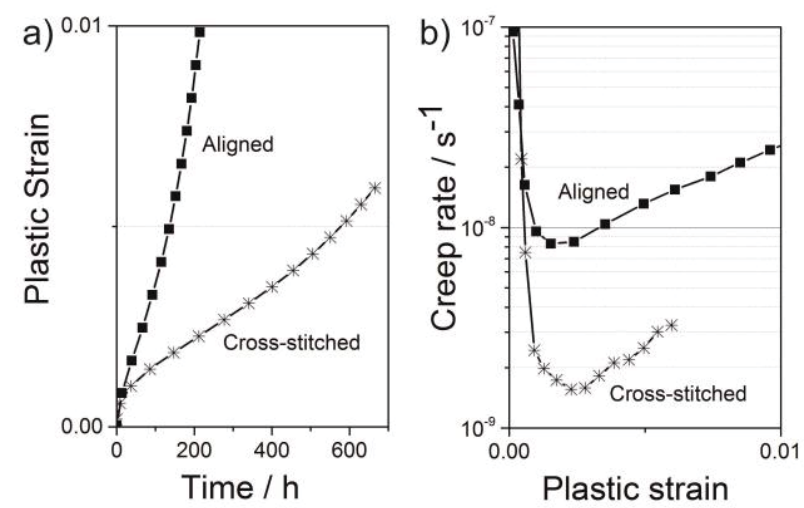

Figure 9. Creep behavior of the aligned and cross-stitched microstructure tested at $650{ }^{\circ} \mathrm{C}$ and $650 \mathrm{MPa}$ : a) the strain versus time and b) logarithmic creep rate versus plastic strain.

\section{Thermal stability}

The thermal stability of an aligned A718Plus microstructure was characterized by long-term heat treatments at $680{ }^{\circ} \mathrm{C}$ and $700{ }^{\circ} \mathrm{C}$. The material studied derives from a study on the influence of thermal exposure below $680{ }^{\circ} \mathrm{C}$ on the mechanical properties of A718Plus and differs slightly from the aligned microstructure tested above [7]. According to Cao et al. thermal exposure can lead to the formation and growth of $\eta / \delta$ phase and the coarsening of $\gamma^{\prime}$-phase [16]. Quantitative analysis of the microstructure reveals that neither the area fraction of $\eta$ phase nor the $\gamma$ grain

Table III. $\gamma$ grain size and $\eta$ area fraction before and after thermal exposure at $680{ }^{\circ} \mathrm{C}$ and $700{ }^{\circ} \mathrm{C}$.

\begin{tabular}{ccc}
\hline state & $\begin{array}{c}\gamma \text { grain size } / \mu \mathrm{m} \\
(\text { median } \pm \sigma)\end{array}$ & $\begin{array}{c}\eta \text {-area fraction } / \% \\
(\text { average } \pm \sigma)\end{array}$ \\
\hline non exposed & $2.6 \pm 2.3$ & $8.8 \pm 0.3$ \\
$680^{\circ} \mathrm{C} / 500 \mathrm{~h}$ & $2.9 \pm 2.3$ & $8.7 \pm 0.2$ \\
$700^{\circ} \mathrm{C} / 500 \mathrm{~h}$ & $2.9 \pm 2.1$ & $8.8 \pm 0.4$ \\
\hline
\end{tabular}
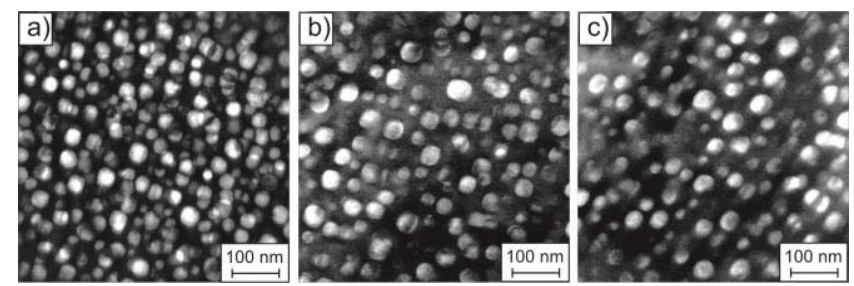

Figure 10. Dark field TEM micrographs of the $\gamma^{\prime}$ precipitates of the a) non exposed b) $680{ }^{\circ} \mathrm{C}$ and c) $700{ }^{\circ} \mathrm{C}$ exposed states.

size changes due to thermal exposure under the test conditions applied (see Table 3). TEM investigations indicate that the $\gamma^{\prime}$ precipitates have slightly coarsened during thermal exposure below $700{ }^{\circ} \mathrm{C}$ (see Figure 10). The relatively slow coarsening behavior of the $\gamma^{\prime}$ phase can be attributed to the influence of $\mathrm{Nb}$ and the resulting reduced effective diffusion coefficient $[16,17]$.

\section{Oxidation resistance}

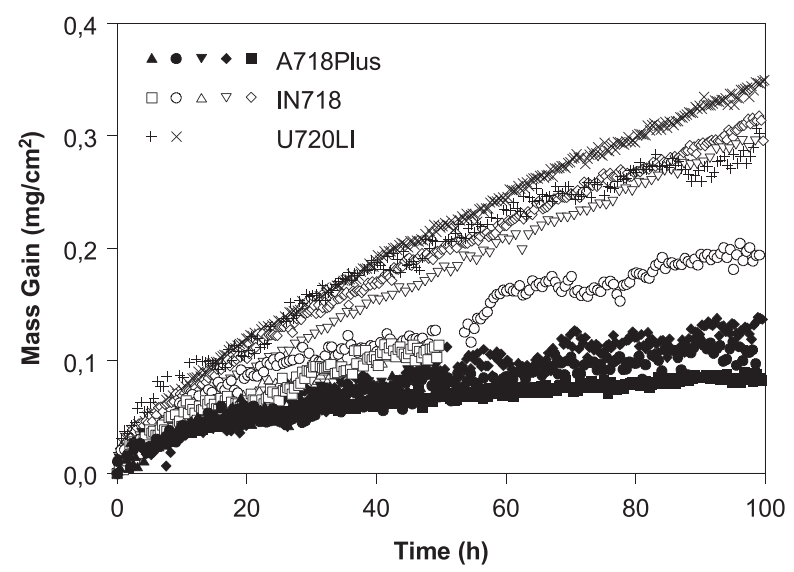

Figure 11. Thermogravimetric mass gain after isothermal exposure at $850{ }^{\circ} \mathrm{C}$ in dry synthetic air.

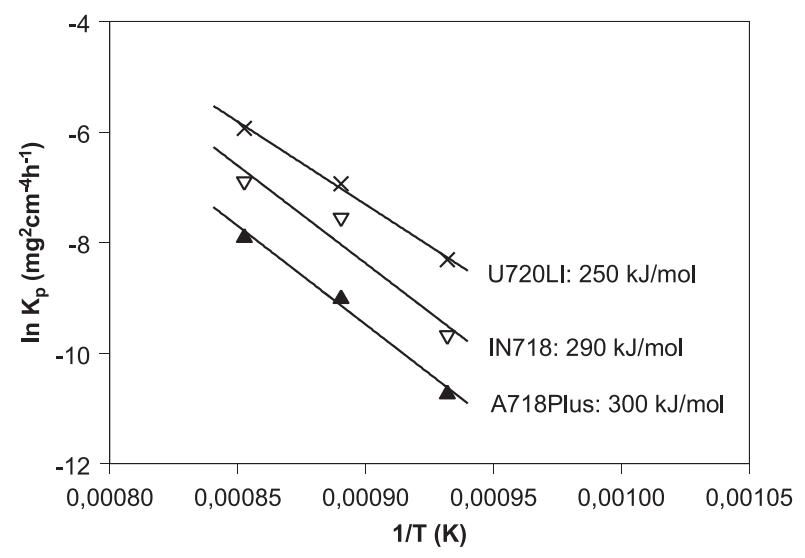

Figure 12. Arrhenius plot with calculated activation energies.

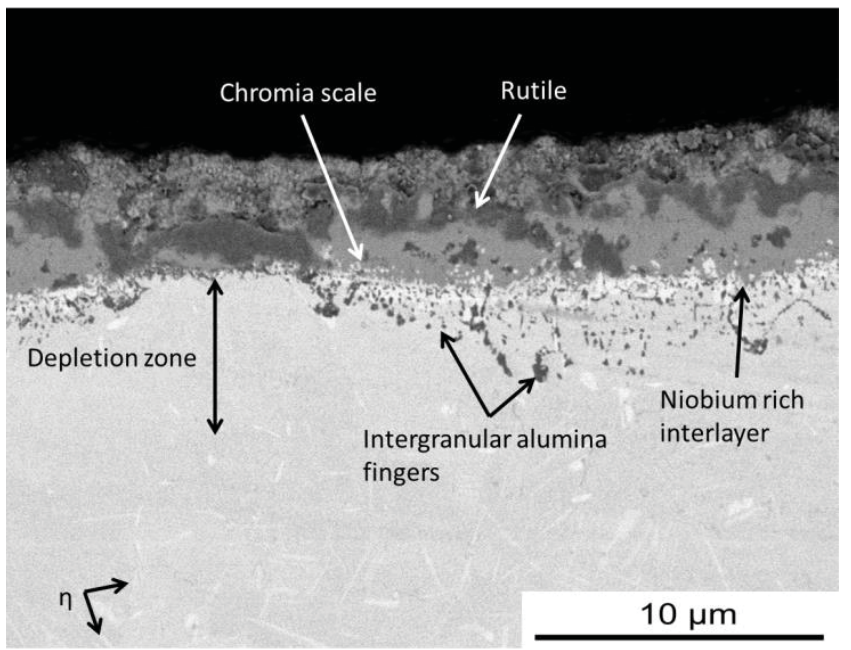

Figure 13. Cross section of A718plus isothermally oxidized at 900 ${ }^{\circ} \mathrm{C}$ for $100 \mathrm{~h}$, the oxide sequence is indicated. 
Alloys like A718Plus, 718 and 720LI have been reported to show parabolic mass gain during isothermal oxidation in dry air [2124]. Figure 11 shows the thermogravimetric analysis obtained after isothermal oxidation at $850{ }^{\circ} \mathrm{C}$. At all investigated temperatures the lowest mass gain was observed for A718Plus and the highest mass gain showed 720LI. The measurements for alloy 718 sit in between both alloys and show significantly more variance. The Arrhenius plot shown in Figure 12 fits the mean results of all oxidation tests. A slightly higher activation energy could be calculated for A718Plus with a value of $300 \mathrm{~kJ} / \mathrm{mol}$ as for 718 with $290 \mathrm{~kJ} / \mathrm{mol}$. Unocic et al. found similar differences, but higher activation energies $(327 \mathrm{~kJ} / \mathrm{mol}$ and $307 \mathrm{~kJ} / \mathrm{mol}$ respectively) in a study covering a lower temperature range [24]. The alloy $720 \mathrm{LI}$ exhibits the lowest activation energy with 250 $\mathrm{kJ} / \mathrm{mol}$ confirming the findings of Chen et al. [21].

During oxidation, A718Plus forms a dense and continuous chromia layer in which rutile is embedded. The position of carbides at the former surface and some remaining matrix material in lower zones of the chromia layer indicate that this layer predominantly grows outwards, with isolated inward growth (see Figure 13). In A718Plus and 718, a thin $\mathrm{Nb}$ containing zone can be found below the chromia layer. With increasing temperature and time this zone is enriching in $\mathrm{Nb}$ but the thickness does not increase.

In contrast to 718 and $720 \mathrm{LI}$, where alumina reaction zones are concentrated along grain boundaries, in A718Plus intragranular alumina zones are formed. Beneath the oxide scale, a zone depleted in $\gamma^{\prime}$ and $\eta$ was observed, characterized by a gradient in layer forming elements. The depletion of $\mathrm{Cr}$ and $\mathrm{Al}$ from the base material to the oxide scale was distinctive, whereas the decrease in $\mathrm{Nb}$ and $\mathrm{Ti}$ was only slightly detectable. The width of the depletion zone increases with oxidation temperature and time. As a result of the solution of the secondary phases beneath the oxide scale, the morphology of $\eta$ should not have a significant influence on the oxidation behavior of A718Plus at high temperatures. In contrast, oxidation at $700{ }^{\circ} \mathrm{C}$ does not cause significant depletion. Figure 14 shows internal oxidation along $\eta$ plates close to the sample's surface revealing that the oxidation process takes place at the interface between $\eta$ and base material. The $\eta$-precipitates seem to play a

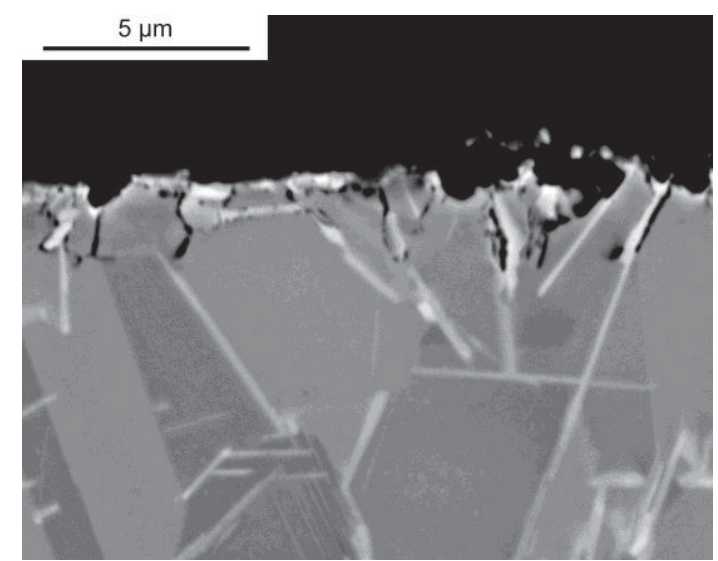

Figure 14. Internal oxidation along $\eta$ phase close to the chromia layer after oxidation at $700{ }^{\circ} \mathrm{C}$ for $2300 \mathrm{~h}$ (oxides and embedding compound appear black).

major role for the oxidation mechanism in providing diffusion paths into the base material leading to internal damage.

\section{Crack Propagation}

Fatigue crack growth (FCG) behavior of superalloys has received a great deal of attention due to being one of the key properties that determines fatigue life of engines (initiation and crack propagation).

In this study, the FCG rates are primarily dependent on the volume fraction, morphology and distribution (orientation) of the $\eta$-phase. The cross stitched microstructure with no preferential orientation of $\eta$-phase reveals an isotropic crack growth behavior with similar crack growth rates in all directions. The FCG rates are slightly lower compared to the FCG rates reported for a similar microstructure tested at $677^{\circ} \mathrm{C}$ and $100 \mathrm{~s}$ dwell time [9], which could be related to the different test conditions. The FCG rates in this study are obtained for a relatively low ASTM grain size number of 6 and an average $\eta$-phase volume content of $6 \%$. For the 'aligned microstructure' an anisotropic crack growth behavior with a low crack propagation rates in two directions and a high crack propagation rate in one direction are observed. A schematic describing how the observed FCP rates relate to the preferential arrangement of the $\eta$-phase is shown in Figure 15. A crack approaching the $\eta$-phase precipitates at an angle of $90^{\circ}$ between applied load and normal of precipitate results in the very low crack propagation rates that are comparable to 720LI [25]. A crack where the loading direction is parallel to the normal of the precipitate $\left(0^{\circ}\right)$ produces the high crack propagation rates exceeding the FCG rates determined for the cross-stitched microstructure.

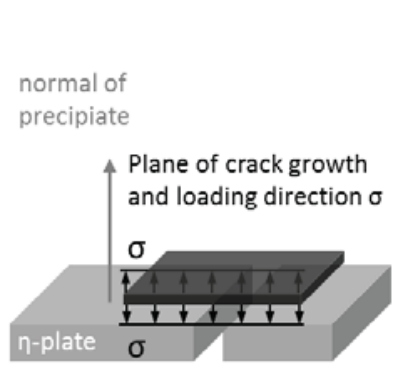

a.)
Plane of crack growth and loading direction $\sigma$

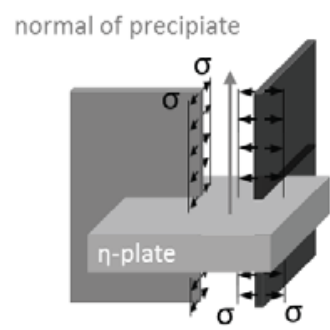

b.)
Figure 15. Schematic showing the plane of crack propagation (dark) in relation to the $\eta$-phase alignment (light grey).

The crack propagation results of the two extreme show that the crack propagation properties can be varied over a wide range. A decrease of the crack propagation rates to a level of $720 \mathrm{LI}$ is possible but creates anisotropic material properties. For the aligned condition, the crack growth rates were determined at trapezoid waveform with $1 \mathrm{~s}$ and $120 \mathrm{~s}$ dwell time in two directions in air and under vacuum to explore the environmental effect on the anisotropic crack growth rates, Figure 18. It appears that an anisotropic crack growth behavior is already present with 1 $\mathrm{s}$ dwell time in air. Comparing the crack growth rates obtained with $1 \mathrm{~s}$ and $120 \mathrm{~s}$ dwell time, it is apparent that the anisotropy of the growth rates in the different directions increases with dwell time. Under vacuum, the crack growth rates in different directions are similar for both $1 \mathrm{~s}$ and $120 \mathrm{~s}$ dwell times. 


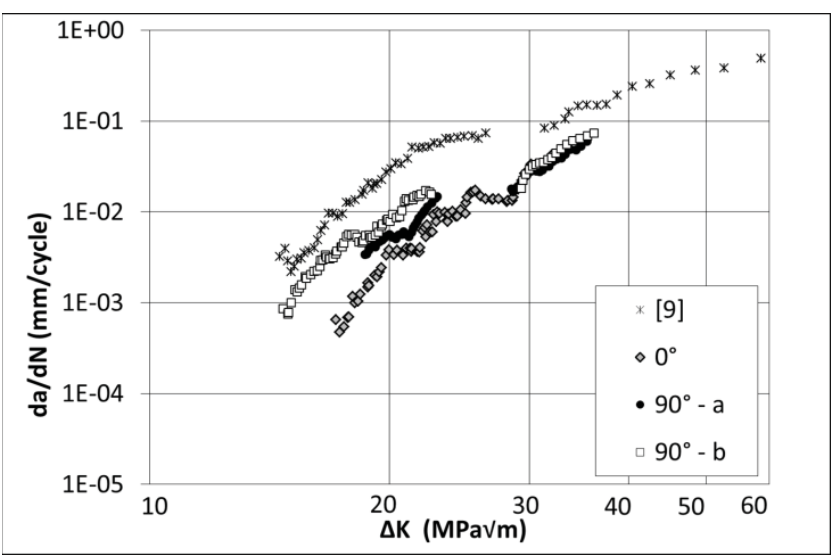

Figure 16. Crack propagation rates (trapezoidal waveform with $120 \mathrm{~s}$ dwell time, $650^{\circ} \mathrm{C}, \mathrm{R}=0.1$ ), [9]: tested at $677^{\circ} \mathrm{C}$ and $100 \mathrm{~s}$ dwell time; cross-stitched microstructure.

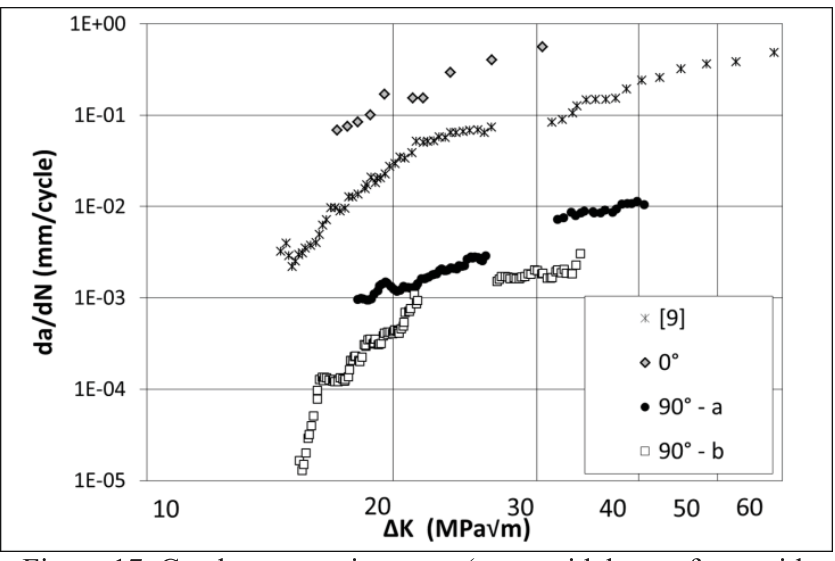

Figure 17. Crack propagation rates (trapezoidal waveform with $120 \mathrm{~s}$ dwell time, $650^{\circ} \mathrm{C}, \mathrm{R}=0.1$ ), [9]: tested at $677^{\circ} \mathrm{C}$ and $100 \mathrm{~s}$ dwell time, aligned microstructure.

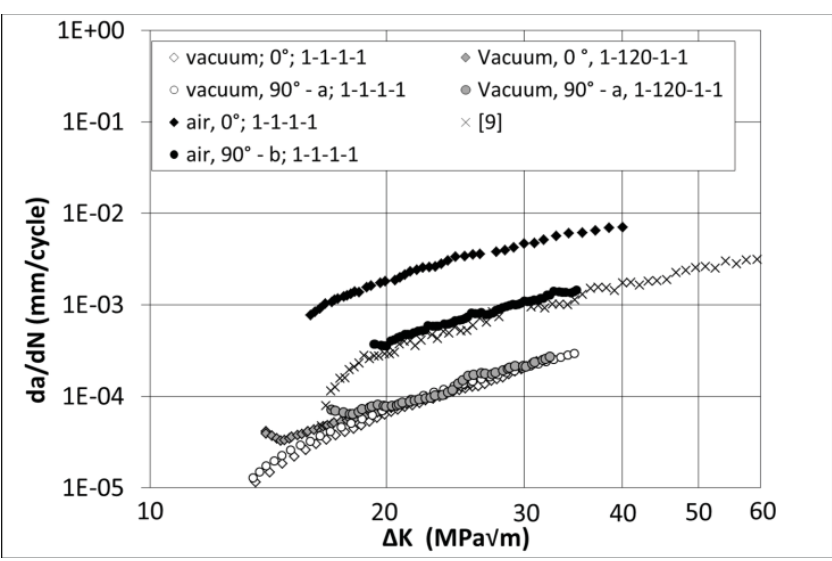

Figure 18. Crack propagation rates (trapezoidal waveform 1-1-1$\left.1,650^{\circ} \mathrm{C}, \mathrm{R}=0.1\right)$, [9]: tested at $677^{\circ} \mathrm{C}$, aligned microstructure.

\section{Crack growth mechanism}

Generally, fatigue crack growth is differentiated in a cycle dependent and time dependent crack growth [10]. At high frequencies and low temperatures predominantly cycle-dependent processes damage superalloys. Cycle-dependent crack growth has been described to be insensitive to variations in microstructure and alloy chemistry. At low frequencies and high temperatures however, the crack growth rates are influenced by time-dependent mechanisms involving creep and environmental degradation processes [10]. The underlying mechanisms involve damage of the material ahead of the crack-tip by creep and stress assisted oxidation/ oxygen embrittlement that increase the crack growth rates [26, 32]. Viskari et al. have shown that a layered oxide scale consisting of $\mathrm{NiO} / \mathrm{Cr}_{2} \mathrm{O}_{3}$ is forming at the crack tip associated with a depletion of $\mathrm{Cr}$ in the matrix. It has been demonstrated that the diffusivity of $\mathrm{Cr}$ and oxygen is enhanced by the applied stress allowing a faster diffusion at the grain boundaries and dislocations [32]. For niobium-containing alloy 718, specific mechanisms have been proposed that involve the preferential oxidation of $\mathrm{NbC}$ and $\mathrm{Ni}_{3} \mathrm{Nb}$ to brittle $\mathrm{Nb}_{2} \mathrm{O}_{5}$ at grain boundaries and the penetration of oxygen ahead of the crack tip leading to enrichment and oxidation of $\mathrm{Nb}$ and $\mathrm{Cr}$ both of which can contribute to enhanced crack growth $[27,28,29]$. A qualitatively similar effect of precipitates in alloy 718 on FCP rates has been reported by Ponelle et al. [30]. With regards to creep, the crack propagation rates are generally considered to decrease with increasing grain size, i.e. a coarse grain alloy version should have higher resistance to timedependent FCG than the fine grained material. This trend has not been found to be true for investigations carried out by Liu et al. on A718Plus [31]. Their experimental results showed that finegrained 718Plus performed better than coarse grain 718Plus under 100 s dwell conditions and that both have very similar FCP rates at baseline (triangular: 1-1-1) conditions.

Liu et al. also reported on the influence of delta phase in A718Plus on crack growth rates. They found that delta phase at the grain boundaries had a small beneficial effect on FCP resistance. The effect was attributed to intrinsic oxidation resistance by trapping oxygen at $\delta$-matrix interfaces or by depleting $\mathrm{Nb}$ in the matrix, reducing the availability for $\mathrm{NbC}$ formation. Furthermore, they suggested that oxidation as well as creep assist in the damage process [31].

Several microstructural observations have been made in this study for both aligned and cross-stitched microstructure under dwell crack propagation conditions in air, along and in close proximity to the primary crack, which helps to elucidate the interaction of $\eta$ phase and crack front:

(a) Weak $\gamma-\eta$ interface: the fatigue crack has been observed to follow the interface between $\gamma$ and $\eta$, even if the interface was not perfectly parallel to the main crack front;

(b) Breakage of $\eta$ particles: the fatigue crack has been observed to run right through $\eta$ precipitates, sometimes through several parallel $\eta$ lamellae;

(c) Intergranular crack growth: clean grain boundaries, without cross-stitched or aligned $\eta$ precipitates have been found to crack in an intergranular manner;

(d) Void formation: voids and small cracks have been found close (up to $10 \mu \mathrm{m}$ away) to the primary crack, they often appear at incoherent $\gamma-\eta$ interfaces;

(e) + (f) Preferential oxidation: $\eta$ particles along primary and secondary cracks often have a porous appearance which indicates oxidation while the surrounding material, is markedly less oxidized.

In the following paragraph, the above microstructural observations are discussed in terms of their potential to retard the dwell fatigue crack propagation rate by dissipation of energy and to explain the mechanical test data.

Studies have shown that (partial) oxidation takes place up to 150 $\mu \mathrm{m}$ ahead of the crack tip [28]. To achieve this, oxygen atoms need to diffuse along grain and phase boundaries and the 


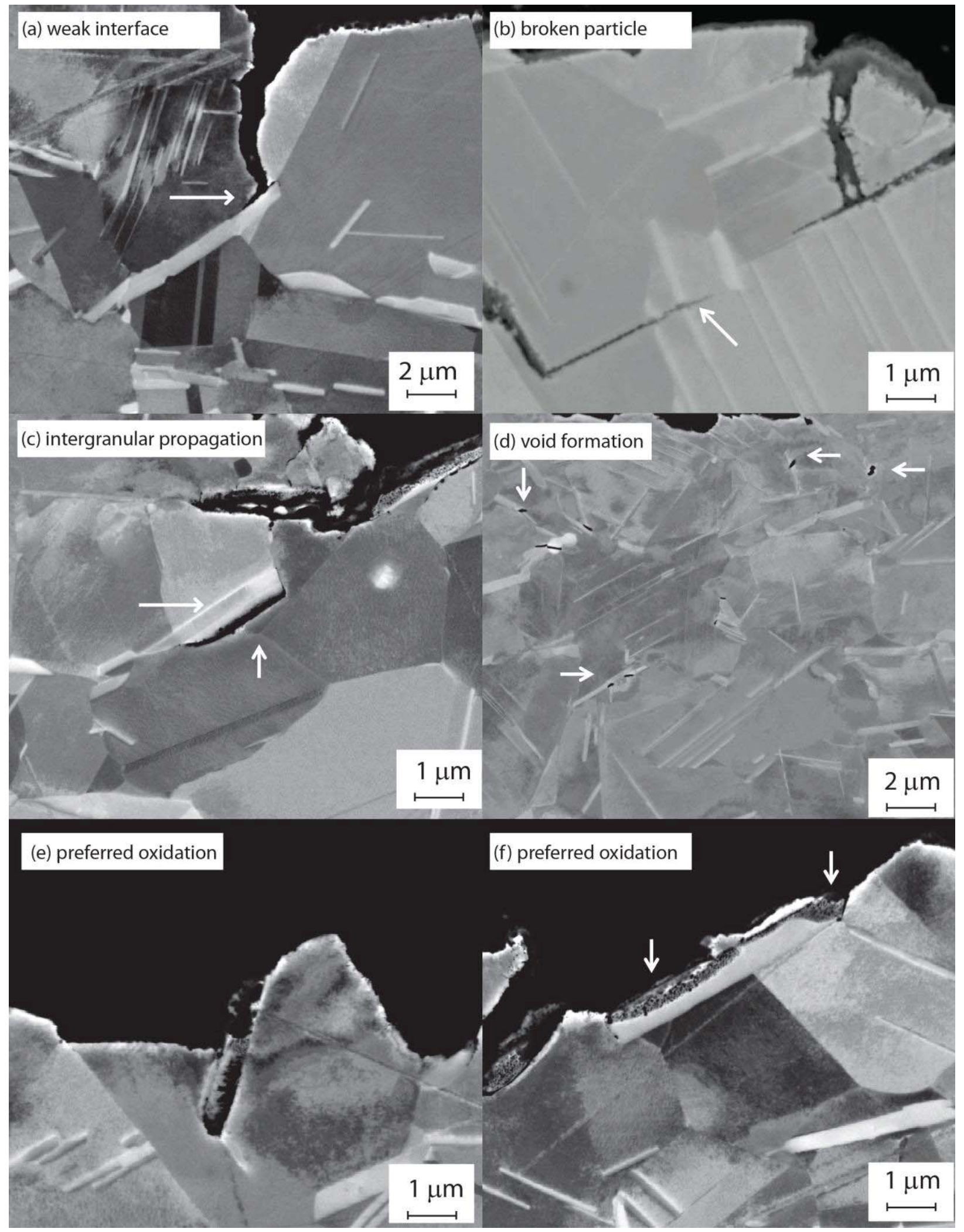

Figure 19. Mechanisms observed during dwell fatigue crack growth in air: a) weak interfaces, guiding crack growth, b) broken $\eta$ particle, c) intergranular crack propagation, d) void formation, $\mathrm{e}+\mathrm{f}$ ) preferred oxidation of $\mathrm{Nb}$ rich $\eta$ precipitates. 
respective boundary type will determine the local diffusion rates. Our interpretation is that a coherent interface is formed between discontinuous $\eta$ and the surrounding matrix [13] which allows less diffusion than an incoherent interface between a blocky $\eta$ precipitate in the aligned microstructure as is shown in Figure 14. The applied stress could enhance the diffusion rates of oxygen and cause a deeper penetration [32]. For a given time step an incoherent interface would oxidize and embrittle further, making the interface weaker than the surrounding material and drive the crack advancement along the $\eta$ particle. A crack will follow a weak interface where the loss of elastic energy released by a crack deviating from the plane normal to the tensile axis, is more than compensated for by the lower fracture energy afforded by the weakened interface. This can lead to localized deviation of the crack path (as illustrated in the Figure 19(a)) and potentially to a pull-out effect. Even after the breakage of the interface, protuberances can become locked in the surrounding material slowing down the crack opening. Broken $\eta$ particles in A718Plus indicate that the interfaces between $\gamma$ and $\eta$ are not always weak and that the interface type may indeed play a significant role. The breakage of particles may also be a function of $\eta$ precipitate thickness since the lamellae in the cross-stitched condition, for which breakage was observed, are much thinner than the blocky type.

Voids formed in the plastic zone ahead of a crack tip are a common feature of ductile fracture and are likely to contribute to the propagation of the main crack particularly in the cross-stitched morphology. In the absence of $\eta$ particles at the grain boundary, the main crack propagation seems to be intergranular.

In order to explain differences between cross-stitched and aligned microstructure, the dominant $\eta$ morphology needs to be taken into account. While the former tends to have fewer and thinner $\eta$ precipitates, coherent with the grain from which they grew, the latter has more and thicker aligned $\eta$ particles which have incoherent interfaces with the matrix. Cross-stitched A718Plus behaves isotropically as its $\eta$ phase has no preferred orientation, which leads to less crack deflection and to a rather continuous crack that breaks the $\eta$ precipitates. There have been no other qualitative observations in this study that would suggest a positive effect of the $\eta$ precipitates that cross-stitch grain boundaries.

Blocky $\eta$ precipitates have the potential to deflect fatigue cracks by offering a lower resistance along its interface, which leads to dissipation of energy by extending the crack path. This is, however, a function of relative orientation of $\eta$ alignment and crack plane, see Figure 15. Aligned $\eta$ can lead to overall faster fatigue crack propagation if the preferred crack plane and plane of $\eta$ plates are parallel to each other as is evidenced by the fatigue crack propagation data $\left(0^{\circ}\right)$ in Figure 17 . It will however lead to fatigue crack propagation rate two orders of magnitude lower in the two orthogonal directions due to repeated deflection of the crack off its main crack path $\left(90^{\circ}-\mathrm{a}, 90^{\circ}-\mathrm{b}\right)$. The differences in FCG rate observed for baseline (1-1-1-1) air conditions indicate that short dwell times are sufficient to cause similar anisotropy, although to smaller extent to those described for $120 \mathrm{~s}$ dwell conditions (Figure 17).

This is reinforced by the FCG rates for the aligned microstructure in vacuum, Figure 17. Baseline FCG rates in vacuum are lower than any other test conditions, highlighting the damaging effect of oxygen in the faster tests in air. More significantly, dwell FCG rates in vacuum are also isotropic and almost as low as the baseline vacuum rates. The small difference in FCG rate can be interpreted as the minor impact that creep has on the damage during fatigue crack propagation of A718Plus.

\section{Summary}

The properties shown for two extremes are investigated within a close collaborative work between Rolls-Royce Deutschland, Otto Fuchs and the Universities of Erlangen-Nürnberg and Cambridge. The obtained knowledge has been used to optimize the microstructure and properties to implement the alloy for high temperature turbine applications in a temperature range where the operation of alloy 718 is limited and the full potential of 720LI is not required. Several conclusions can be drawn from the investigations:

- The properties of A718Plus can be varied in a wide range and are dependent on the thermo-mechanical processing history and heat treatment.

- $\quad$ The tensile strength can be enhanced by $190 \mathrm{MPa}\left(600^{\circ} \mathrm{C}\right)$ by increasing the ASTM grain size.

- The creep properties are dependent on the amount of precipitated $\eta$ determining the amount of $\gamma^{\prime}$ phase. The competing properties creep and crack propagation needs to be carefully balanced.

- Oxidation resistance of A718Plus is superior compared to the alloys 718 and 720LI.

- The crack propagation properties can be lowered to the level of 720LI with the detriment of creating anisotropic material properties. Since the direction of the alignment is predictable, the alignment and residual crack growth rates can be adjusted in that way that they oppose the main stresses in a component.

\section{Acknowledgments}

The work was conducted as a part of the German-funded research program RoKoTec (LuFoIV) and supported by the Bundesministerium für Wirtschaft und Technologie (BMWi) under grant number 20T0813.

The authors acknowledge the support and assistance of Mathias Röth from Rolls-Royce Deutschland for their professional assistance.

\section{References}

1. M. Springmann, W. Rothkegel, D. Huenert, H. Schlums, "Introduction of the new nickel-base alloy ATI 718Plus for critical parts", 7th International Conference on Low Cycle Fatigue, September 9-11, 2013, Aachen.

2. A. Casanova, N. Martín-Piris, R. Krakow, M. Hardy and C. Rae, "Evolution of secondary phases in alloy ATI 718Plus ${ }^{\circledR}$ during processing”, Eurosuperalloys 2014, May 12-14, Nizza.

3. A. Casanova, M. Hardy, C. Rae, "MORPHOLOGY AND KINETICS OF GRAIN BOUNDARY PRECIPITATION IN ALLOY ATI 718PLUS®", 8th International Symposium on Superalloy 718 and Derivatives, September 28-October 1, 2014, Pittsburgh, Pennsylvania.

4. R. Krakow, M.C. Hardy, C.M.F. Rae and P.A. Midgley, "High Resolution Orientation Mapping of Secondary Phases in ATI 718Plus ${ }^{\circledR}$ Alloy”, Eurosuperalloys 2014, May 12-14, Nizza.

5. K. Löhnert, Dissertation, University Erlangen -Nürnberg, 2011. 
6. O.M. Messé, J.S. Barnard, E.J. Pickering, P.A. Midgley and C.M.F. Rae (2014), "On the precipitation of delta phase in ALLVAC® 718Plus", Philosophical Magazine, DOI: 10.1080/14786435.2013.878052.

7. M. Pröbstle, S. Neumeier, D. Hünert, M. Göken, "Tensile and creep strength of thermally exposed ATI 718Plus", 8th International Symposium on Superalloy 718 and Derivatives, September 28-October 1, 2014, Pittsburgh, Pennsylvania.

8. D. Rossouw, R. Krakow, Z. Saghi, C. Yeoh, P. Burdet, R. K. Leary, F. de la Peña, C. Ducati, C.M.F. Rae, P.A. Midgley, "Blind source separation aided characterization of the $\gamma^{\prime}$ strengthening phase in an advanced nickel-based superalloy by spectroscopic 4D electron microscopy", Advanced Materials, submitted 2015.

9. 718 Plus ${ }^{\circledR}$ Data Sourcebook, ATI Allvac, Version 1.0, September 10, 2008.

10. X. Liu, S. Rangararan, E. Barbero, K.-M. Chang, W.-D. Cao, R. Kennedy, T. Carneiro, "FATIGUE CRACK PROPAGATION BEHAVIORS OF NEW DEVELOPED ALLVAC ${ }^{\circledR}$ 718PLUSTM SUPERALLOY”, Superalloys 2004, TMS (The Minerals, Metals \& Materials Society), 2004, p 283-290.

11. W. D. Cao and R. Kennedy; Role of chemistry in 718-type alloys--Allvac718Plus ${ }^{\mathrm{TM}}$ alloy development; Superalloys (2004)

12. W. D. Cao; Solidification and solid state phase transformation of Allvac 718Plus ${ }^{\mathrm{TM}}$ alloy; Superalloys 718, 625, 706 and Derivatives (2005)

13. E.J. Pickering and H. Mathur and A. Bhowmik and O.M.D.M. Messe and J.S. Barnard and M.C. Hardy and R. Krakow and K. Loehnert and H.J. Stone and C.M.F. Rae; Grain-boundary precipitation in Allvac 718Plus, Acta Materialia (2012)

14. E.I. Galindo-Nava, L.D. Connor, C.M.F. Rae, "On the prediction of the yield stress of unimodal and multimodal $\gamma^{\prime}$ Nickel-base superalloys", Acta Materialia 98 (2015) 377-390.

15. Chaturvedi, M. and Han, Y., "Creep deformation of Alloy 718”. Superalloys 718, (1989), 489-498.

16. Cao, W.D., "Thermal Stability Characterization of Ni-Base ATI 718Plus", Superalloys (2008), 789-797.

17. X. Xie, G. Wang, J. Dong, C. Xu, W.-D. Cao, R. Kennedy, "STRUCTURE STABILITY STUDY ON A NEWLY DEVELOPED NICKEL-BASE SUPERALLOY_ALLVAC $®$ 718PLUSTM", Superalloys 718, 625, 706 and Derivatives, 2005.

18. Unocic, R.R., Viswanathan, G.B., Sarosi, P.M., Karthikeyan, S., Lia, J. and Mills, M.J., "Mechanisms of creep deformation in polycrystalline Ni-base disk superalloys". Material Science and Engineering, 483-484, (2008), 25-32.

19. Kozar, R.W., Suzuki, A., Milligan, W.W., Schirra, J.J., Savage, M.F. and Pollockr, T.M., "Strenghtening mechanisms in polycrystalline multimodal nickel-base superalloys", Metallurgical and Materials Transactions A, 40, (2009), 15881603.
20. Hüther, W. and Reppich, B., "Interaction of dislocations with coherent, stress-free, ordered particles”, Z. Metallkde. 69, (1978), $628-634$

21. J.H. Chen, P.M. Rogers, J.A. Little, "OXIDATION BEHAVIOR OF SEVERAL CHROMIA-FORMING NICKELBASE SUPERALLOYS", Oxidation of Metals, Vol. 47, Nos. 5/6, 1997, S. $381 \mathrm{ff}$.

22. L. Geng, Y. Na, N. Park, "OXIDATION BEHAVIOR OF ALLOY 718 AT HIGH TEMPERATURE”, Materials and Design 28, 2007, S. $978 \mathrm{ff}$.

23. K.A. Unocic, R.R. Unocic, B.A. Pint, R.W. Hayes, "EFFECT OF MICROSTRUCTURE AND ENVIRONMENT ON THE HIGH-TEMPERATURE OXIDATION BEHAVIOR OF ALLOY 718PLUS", 7th International Symposium on Superalloy 718 and Derivates, The Minerals, Metals \& Materials Society, 2010, S. $977 \mathrm{ff}$.

24. K.A. Unocic, B.A. Pint, "EFFECT OF ENVIRONMENT ON THE HIGH TEMPERATURE OXIDATION BEHAVIOUR OF 718 AND 718 PLUS", 8th International Symposium on Superalloy 718 and Derivates, The Minerals, Metals \& Materials Society, 2014, S. 909ff.

25. S. Everitt, Dissertation, University of Southhampton, 2012.

26. D.A. Woodford, "Gas phase embrittlement and time dependent cracking of nickel based superalloys", Energy Materials, 2006, vol 1, No1, p59-79.

27. C.F. Miller, G.W. Simmons, R.P. Wie, "HIGH TEMPERATURE OXIDATION OF Nb, NbC AND Ni3Nb and OXYGEN ENHANCED CRACK GROWTH", Sripta mater. 42 (2000) 227-232.

28. C.F. Miller, G.W. Simmons, R.P. Wie, "MECHANISM FOR OXYGEN ENHANCED CRACK GROWTH IN INCONEL 718", Scripta mater. 44 (2001) 2405-2410.

29. R. M. KEARSEY, J. TSANG, S. OPPENHEIMER and E. MCDEVITT, „Microstructural Effects on the Mechanical Properties of ATI 718Plus ${ }^{\circledR}$ Alloy“, JOM, Vol. 64, No. 2, 2012, DOI: $10.1007 / \mathrm{s} 11837-012-0242-3$.

30. S. Ponelle, B Brethes, A. Pineau, "Orientational effects and influence of delta phase on fatigue crack growth rates in a forged disc of Inco718 superalloy", $718 \&$ Derivatives, The Minerals, Metals \& Materials Society, 2001, p501-510.

31. X. Liu, J. Xu, N. Deem, K.-M. Chang, E. Barbero, W.-D. Cao, R.L. Kennedy, T. Carneiro, "EFFECT OF THERMALMECHANICAL TREATMENT ON THE FATIGUE CRACK PROPAGATION BEHAVIOR OF NEWLY DEVELOPED ALLVAC® 718PLUS ALLOY”, Superalloys 718, 625, 706 and Derivatives, 2005.

32. L. Viskari, M. Hörnqvist, K.L. Moore, Y. Cao, K. Stiller, "Intergranular crack tip oxidation in a Ni-base superalloy", Acta Materialia 61 (2013) 3630-3639. 